\title{
CrystEngComm
}

Cite this: CrystEngComm, 2014, 16 3515

Received 21st November 2013, Accepted 11th February 2014

DOI: $10.1039 / c 3 c e 42379 d$

www.rsc.org/crystengcomm

\section{A combinatorial study of the mechanical and magnetic properties of a gradually nitrided austenitic stainless steel single crystal}

\author{
E. Menéndez, ${ }^{\star a b}$ C. Templier, ${ }^{c}$ G. Abrasonis, ${ }^{d}$ J. F. Lopez-Barbera, ${ }^{b}$ J. Nogués, ${ }^{* b e}$ \\ K. Temst ${ }^{a}$ and J. Sort ${ }^{\text {ef }}$
}

\begin{abstract}
The mechanical and magnetic properties of a nitrided austenitic stainless steel are studied using a combinatorial approach. Plasma nitriding of a [100]-oriented $316 \mathrm{~L}$ single crystal is carried out using a loose shadow mask to produce an in-plane lateral gradient of nitrogen concentration that extends up to $100 \mu \mathrm{m}$. The local mechanical and magnetic properties across the gradually nitrided area are resolved by nanoindentation and the polar magneto-optic Kerr effect, respectively. The hardness, reduced Young's modulus and remanence qualitatively depict the nitrogen profile, suggesting that the nitrogen concentration is a central effect for these observed dependencies. Conversely, the coercivity exhibits a nonmonotonic behaviour due to the interplay between magnetic anisotropy and the strength of the induced ferromagnetism. Fingerprints of the expected transition from a nitrogen supersaturated solid solution to

a multiphase nature of expanded austenite are evidenced along the gradually nitrided area.
\end{abstract}

\section{Introduction}

The combinatorial methodology consists of the simultaneous synthesis of materials with a wide range of compositions. ${ }^{1-3}$ This is a very powerful approach to discover new materials or to gain understanding of the dependence of the materials properties on the composition. It has been employed in different science and technology areas such as catalysis, superconductivity, optics or magnetism..$^{1,2,4-6}$ However, its use in thermo-chemical treatments of materials is rather scarce. ${ }^{7}$ These treatments consist of saturating the near surface layers of a given material with interstitial or substitutional species from a saturating environment (solid, liquid, gas or plasma) and are used in a wide variety of surface modification processes such as nitriding or carburizing. Depending on its atomic ratio, the saturating element affects the microstructure and, thus, the properties of the thermo-chemically treated material. Consequently, the use of combinatorial

\footnotetext{
${ }^{a}$ Instituut voor Kern- en Stralingsfysica, KU Leuven, Celestijnenlaan 200 D, BE-3001 Leuven, Belgium.E-mail: Enric.MenendezDalmau@fys.kuleuven.be; Tel: $+32(0) 16327145$

${ }^{b}$ ICN2 - Institut Catala de Nanociencia i Nanotecnologia, Campus UAB, 08193 Bellaterra, Barcelona, Spain. E-mail: Josep.Nogues@uab.cat; Tel: +34937371604 ' Institut P', Université de Poitiers \& ENSMA, 86962 Futuroscope-Chasseneuil, France ${ }^{d}$ Institute of Ion Beam Physics and Materials Research, Helmholtz-Zentrum Dresden - Rossendorf, P. O. Box 510119, 01314 Dresden, Germany ${ }^{e}$ ICREA - Institució Catalana de Recerca i Estudis Avançats, Barcelona, Spain ${ }^{f}$ Departament de Física, Facultat de Ciències, Universitat Autònoma de Barcelona, E-08193 Bellaterra, Spain
}

approaches in these materials would render a simple means to optimize their performance for specific applications. In this context, we present a combinatorial study on the influence of the concentration of $\mathrm{N}$ on the functional (magnetic and mechanical) properties of a 316L austenitic stainless steel (ASS) single crystal.

Nitriding of austenitic stainless steels at moderate temperatures (e.g., $400{ }^{\circ} \mathrm{C}$ ) is a common route to improve their surface mechanical properties since nitriding leads to an enhanced hardness ${ }^{8}$ and wear resistance ${ }^{9}$ without compromising the corrosion resistance. ${ }^{10}$ After nitriding, ASSs also become ferromagnetic by means of the formation of the so-called expanded austenite phase $\gamma_{\mathrm{N}}{ }^{10-14}$ which, rather than a supersaturated nitrogen solid solution, shows a multiphase nature consisting of nanometric $\mathrm{CrN}$ precipitates embedded in a $\mathrm{Fe}_{4} \mathrm{~N}$-like matrix. ${ }^{15}$ The nitrided top layer is not homogeneous along the depth of the sample, exhibiting a combination of interconnected gradients, such as $\mathrm{N}$ concentration, ${ }^{16,17}$ residual stress, ${ }^{18}$ stacking fault density ${ }^{18}$ or lattice rotation, ${ }^{19,20}$ which yields a graded material along the depth. Since these factors and, particularly, the nitrogen concentration play a key role in determining the mechanical and magnetic characteristics of the expanded austenite phase, a direct correlation between these parameters and the resulting properties is of particular interest to establish the functional performance of nitrided ASSs. While composition, residual stress and stacking fault density depth distributions can be determined by non-destructive measurements, ${ }^{21}$ a destructive time-consuming successive partial removal of the material is 
often necessary to obtain the mechanical depth profiles (e.g., nanoindentation tomography). ${ }^{22}$ Therefore, routes able to give insight into the influence of the $\mathrm{N}$ content on the mechanical and magnetic properties, while avoiding either destructive procedures (i.e., partial layer removal) or the tedious production of diverse samples with dissimilar surface $\mathbf{N}$ contents, are of particular scientific and technological interest. Here, a fast and versatile approach to obtain at once (i.e., with a single nitriding procedure) an in-plane (i.e., lateral) gradient of the nitrogen content at the surface of a $316 \mathrm{~L}$ ASS single crystal, resulting in a graded expanded austenite, is presented. This offers the possibility to study, in a straightforward and non-destructive manner, the changes induced in the mechanical and magnetic properties as a function of the amount of nitrogen which is incorporated in the austenite phase in a single sample. Since the properties of ASSs, such as mechanical behaviour ${ }^{22}$ or nitrogen diffusivity, ${ }^{23-25}$ strongly depend on the crystalline orientation, a [100] ASS single crystal rather than a polycrystalline sample has been chosen. This also avoids the influence of grain boundaries and intergrain interactions on the resulting stress state and magnetic properties of the expanded austenite. ${ }^{12,13}$

\section{Experimental}

A disk-shaped 316L ASS single crystal (1 cm in diameter and $2 \mathrm{~mm}$ thick) with the [100] crystalline orientation was half masked by placing a $200 \mu \mathrm{m}$ thick Si wafer. Subsequently, it was plasma-nitrided for 60 minutes at $400{ }^{\circ} \mathrm{C}$. Prior to nitriding, the sample was mechanically polished in various steps with progressively smaller abrasive particles until mirror-like appearance was achieved. For the final polishing step, $0.05 \mu \mathrm{m}$ colloidal silica particles were used for $20 \mathrm{~min}$ in order to minimize residual work-hardening. ${ }^{19}$ The specimen was subsequently nitrided in the URANOS reactor $^{26}$ where plasma is created in a quartz tube using a 13.56 $\mathrm{MHz}$ electromagnetic excitation with an incident input power of $700 \mathrm{~W}$. The treatment was carried out under suspended potential conditions. The sample was heated in vacuum up to $380{ }^{\circ} \mathrm{C}$. Then, the chamber was fed with a gas mixture of $60 \mathrm{sccm} \mathrm{N}_{2}+40 \mathrm{sccm} \mathrm{H}$, the total pressure was regulated at $7.5 \mathrm{~Pa}$ and the plasma ignited. After creating the plasma, the temperature increased up to $400{ }^{\circ} \mathrm{C}$ in 15 minutes, remaining constant for the rest of the treatment (i.e., nitriding time). The mask was not mechanically clamped during nitriding (i.e., not well adhered to the sample surface), allowing the plasma to be partially active at the edge of the mask, thus reducing its shadowing effect (Fig. 1a). ${ }^{27}$ This masking creates a lateral nitrogen profile underneath the masked area, resulting in a [100] single crystalline-like expanded austenite with an in-plane gradient of the surface $\mathrm{N}$ content. White light interferometry (WLI), using a Talysurf CCI 6000 3D optical profiler operating with Mireau interference objectives, has been employed to investigate the surface topography. The lateral $\mathrm{N}$ profile along the direction perpendicular to the boundary between the fully
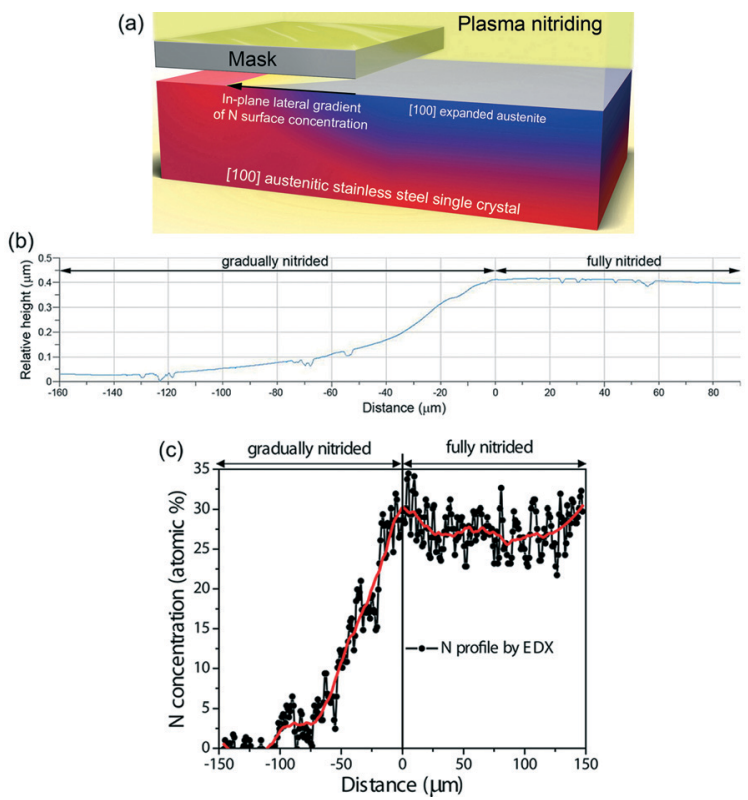

Fig. 1 (a) Schematic representation of the nitriding process using a mask (dimensions not to scale), (b) WLI topographic profile and (c) EDX nitrogen profile along the direction perpendicular to the edge of the mask, i.e., from the non-nitrided to the fully nitrided areas. The red solid line is the result of data smoothing.

and gradually nitrided areas was determined using energy dispersive X-ray analysis (EDX; MERLIN scanning electron microscope from Zeiss). The obtained $\mathrm{N}$ profile is the result of averaging over the $\mathrm{N}$ concentration profile in the upper $40 \mathrm{~nm},{ }^{28}$ which approximately corresponds to the depth probed by EDX under the employed conditions (2 $\mathrm{keV}$ of acceleration voltage). Note that since the electron depth penetration is roughly inversely proportional to the density ${ }^{28}$ and the density slightly varies along the gradually nitrided area, the depth penetration is not exactly constant. Actually, the probed depth in the non-nitrided areas (density $\approx 7.9 \mathrm{~g} \mathrm{~cm}^{-3}$ ) is around $36 \mathrm{~nm}$, whereas the one corresponding to an area with 20 at.\% of incorporated $\mathrm{N}$ (density $\approx 6.6 \mathrm{~g} \mathrm{~cm}^{-3}$ ) 13 is about $43 \mathrm{~nm}$. The evolution of the local mechanical properties has been resolved by nanoindentation using a UMIS instrumented nanoindenter from Fischer-Cripps Laboratories. Measurements were performed in load-control mode, with a maximum applied load of $1 \mathrm{mN}$, using a Berkovich pyramidal-shaped diamond tip. This results in indentation print sizes in the range $250-400 \mathrm{~nm}$. The thermal drift was always kept below $\pm 0.05 \mathrm{~nm} \mathrm{~s}^{-1}$. The hardness $H$ was evaluated from the load-displacement curves at the beginning of the unloading segments using the method by Oliver and Pharr. ${ }^{29,30}$ Proper corrections for the contact area (calibrated using a fused quartz sample), instrument compliance and initial penetration depth have been applied to obtain reliable values of the hardness and reduced Young's modulus. The evolution of the local magnetic properties has been investigated using a Durham Magneto Optics Ltd polar magnetooptic Kerr effect (MOKE) apparatus with a laser spot focused down to around $3 \mu \mathrm{m}$. Remarkably, taking advantage of the 
interplay between the nature of the mask (i.e., material) and its adhesion to the sample surface (e.g., partial contact or full adhesion, for instance by using pre-lithographed substrates and subsequent post-deposition), the extent of the lateral $\mathrm{N}$ penetration might be controlled, ranging from pronounced and broad to nearly uniform but limited lateral gradient profiles. The latter would take advantage of the intrinsic lateral penetration of the plasma. To further minimize this lateral penetration, ion beam nitriding rather than plasma nitriding, could be used due to its directionality and the possibility to focus the beam. Room temperature $\mathrm{N}$ ion implantation would even result in decreased lateral ranges.

\section{Results and discussion}

In agreement with the literature, ${ }^{31}$ white light interferometry measurements (Fig. 1b) confirm that plasma nitriding induces a swelling of about $350 \mathrm{~nm}$ in the fully nitrided area. Further, the results reveal a rather linear gradual decrease of the swelling away from the mask edge, reaching about $100 \mu \mathrm{m}$ of lateral distance. The thickness of the nitrided layer under such nitriding conditions (i.e., $400{ }^{\circ} \mathrm{C}$ for 1 hour) extends only up to around $2.5 \mu \mathrm{m} .{ }^{13}$ Therefore, rather than a pure lateral diffusion underneath the mask, which would induce a limited lateral penetration in the $\mu \mathrm{m}$ range, ${ }^{27}$ this gradual topographic feature is ascribed to the activity of the plasma at the edge of the mask, leading to intermediate nitriding conditions and, thus, to different degrees of swelling.

As can be seen in Fig. 1c and 2a, the energy dispersive $\mathrm{X}$-ray analysis nitrogen profile clearly shows that the $\mathrm{N}$ content decreases as one moves away from the edge of the mask. This extends up to around $100 \mu \mathrm{m}$ under the masked area, depicting to some extent the topographic step and,
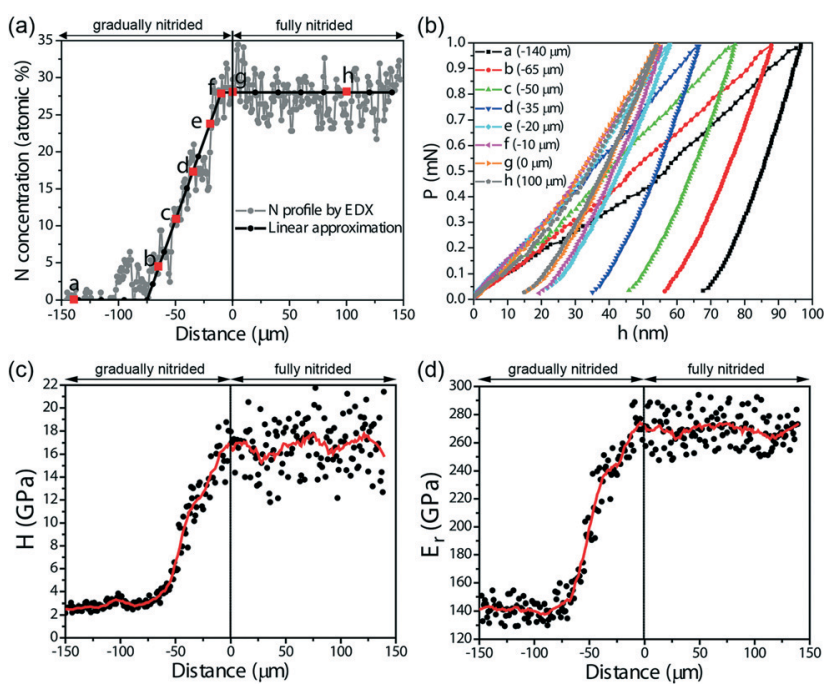

Fig. 2 (a) EDX $N$ profile where the local areas are assessed by nanoindentation are highlighted. (b) Load (P)-displacement (h) indentation curves. Evolution of (c) the hardness $\mathrm{H}$ and (d) the reduced indentation modulus $E_{\mathrm{r}}$ along a gradually nitrided area. The red solid lines are the result of data smoothing. thus, confirming the production of an in-plane nitrided system with a graded surface $\mathrm{N}$ content.

In order to spatially resolve the evolution of the mechanical properties along the gradually nitrided area, nanoindentation measurements have been carried out in lateral steps of $1 \mu \mathrm{m}$. As can be clearly seen in Fig. 2b, the maximum displacement $h$ (i.e., penetration) inversely scales with the $\mathrm{N}$ content, indicating a higher resistance to penetration (and hence an enhanced hardness) as the measurements are carried out from the non-nitrided to the fully nitrided areas. Fig. 2c and $\mathrm{d}$ show the evolution of the hardness $H$ and the reduced Young's modulus $E_{\mathrm{r}}$ along the gradually nitrided area. Both parameters exhibit progressively higher values as the assessed areas become closer to the fully nitrided volume, qualitatively mimicking the $\mathrm{N}$ profile. For instance, in agreement with previously reported results, ${ }^{22}$ the hardness $H$ is around $2.5 \mathrm{GPa}$ in the non-nitrided areas and $16 \mathrm{GPa}$ in the fully nitrided counterpart. Due to the perpendicular depth gradient of $\mathrm{N}$ concentration, a quantitative correlation between $H, E_{\mathrm{r}}$ and $\mathrm{N}$ concentration is not straightforward. However, the fact that the $H$ and $E_{\mathrm{r}}$ lateral profiles image the $\mathrm{N}$ lateral profile suggests that the $\mathrm{N}$ content is a key tuning parameter for the observed changes in the mechanical properties. A multiphase nature of expanded austenite, which develops as the $\mathrm{N}$ content increases, has been recently reported. This consists of $\mathrm{CrN}$ nanometric precipitates embedded in a $\mathrm{Fe}_{4} \mathrm{~N}$-like matrix whose formation is linked to the amount of nitrogen. ${ }^{15}$ Therefore, while the enhanced hardness in the low $\mathrm{N}$ content region of the profile may be mostly ascribed to solid solution hardening processes, a combination of solid solution and precipitation hardening is expected when probing the areas close to the fully nitrided region.

The dispersion of the mechanical parameters broadens, as the assessed areas are closer to the partially/fully nitrided interface. This might be attributed to either local compositional inhomogeneities, variations in density of defects or local roughness. Eventually, these local inhomogeneities might be due to the presence of the precipitates within the matrix of the expanded austenite, which would be in agreement with the expected multiphase nature of this region. Nevertheless, although atomic force microscopy imaging of the fully nitrided areas reveals rather flat surfaces with a root mean square roughness of around $7 \mathrm{~nm}$ (note that the pristine areas show decreased roughness with root mean square values between 2-4 $\mathrm{nm}$ ), a certain contribution to this dispersion broadening from local roughness cannot be completely ruled out. ${ }^{29}$

Fig. 3 shows the polar magneto-optic Kerr effect (MOKE) loops corresponding to different localized areas (schematically represented in panel a) along the gradually nitrided areas. The fully nitrided areas exhibit a rather square-shaped loop, evidenced by a high remanence (loop A), in agreement with the easy axis behaviour of [100] expanded austenite produced at $400{ }^{\circ} \mathrm{C} .{ }^{13}$ This is mainly ascribed to the interplay between a large out-of-plane lattice expansion and the expected presence of $\mathrm{Fe}$ and Ni-enriched areas due to the multiphase nature of expanded austenite. For the measured 

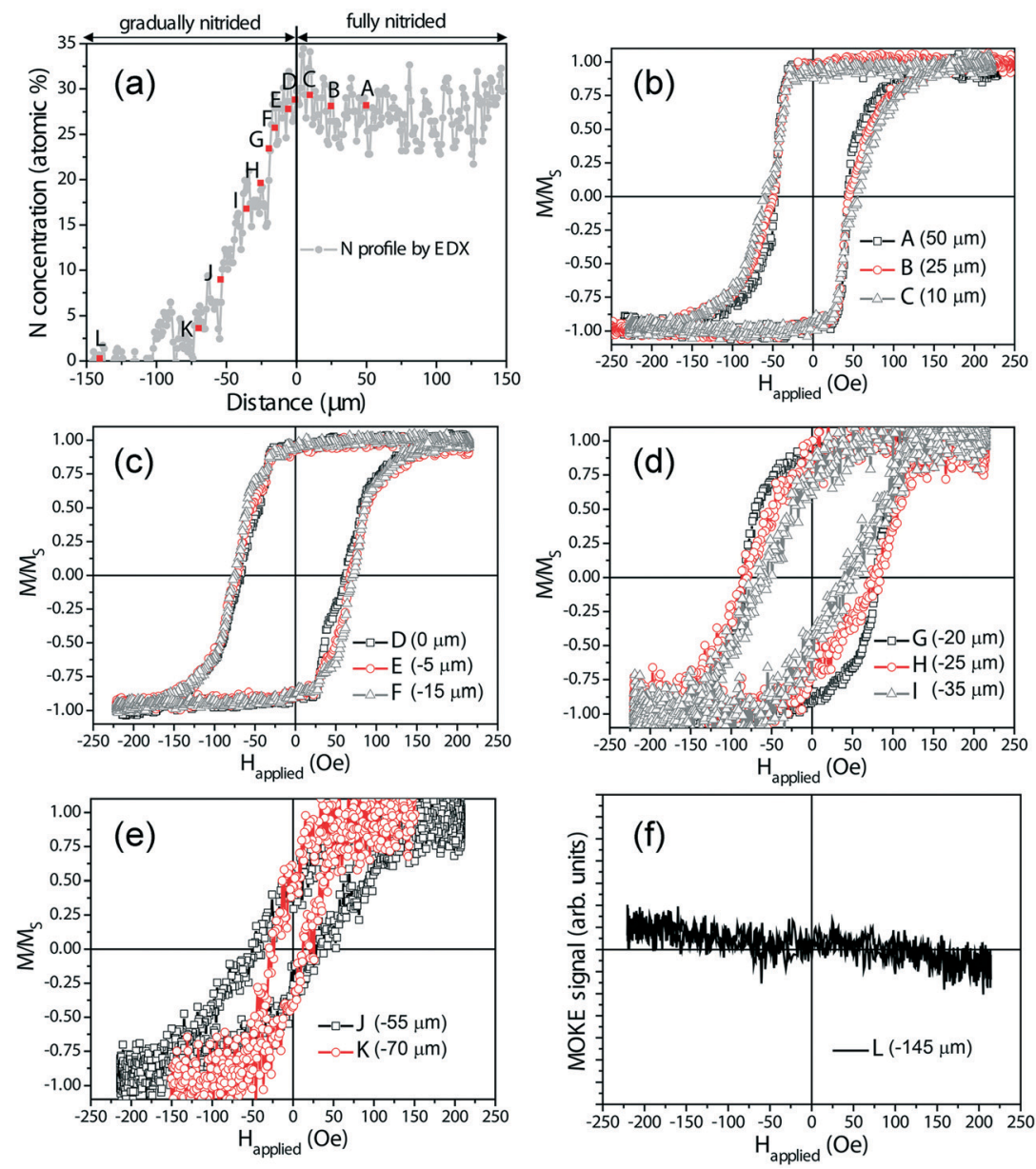

Fig. 3 (a) EDX N profile where the local areas are assessed by MOKE are highlighted. The polar MOKE loops for the different areas are shown in panels (b)-(f).

areas closer to the shadow edge (e.g., loops $\mathrm{B}, \mathrm{C}$ or $\mathrm{D})$, the hysteresis loops show more gradual magnetization reversals (i.e., more tilted branches, exhibiting a broader distribution of switching fields) and incipient traces of other magnetic contributions as a result of the variations in the $\mathrm{N}$ profile. Two-step loops with tilted branches are discernible close to the edge and the adjacent gradually nitrided area (loops $\mathrm{E}$ and $\mathrm{F}$ in Fig. 3c). Since the area probed by the laser spot of the MOKE is around $3 \mu \mathrm{m}$ and the measurements are performed in steps of $5 \mu \mathrm{m}$, the two step-like loops might be the result of assessing areas with dissimilar $\mathrm{N}$ contents. Further within the gradually nitrided area, the different magnetic contributions seem to merge in a rather rounded hysteresis loop (loop G). This could be correlated with the incipient loss of the multiphase nature of expanded austenite, starting to behave as a single phase (i.e., as a nitrogen supersaturated solid solution) with a less pronounced ferromagnetic character. Beyond around $20 \mu \mathrm{m}$ from the edge (i.e., below $\approx 23$ at.\% of $\mathrm{N}$; regions $\mathrm{H}$ and $\mathrm{I}$ ), the MOKE measurements exhibit significantly lower remanences, in agreement with a lower amount of incorporated nitrogen and thus a less pronounced out-of-plane expansion of the lattice cell, leading to a weaker perpendicular anisotropy.
Concomitantly, the signal to noise ratio noticeably worsens, which is consistent with the weak ferromagnetic character of expanded austenite for low $\mathrm{N}$ contents. In the framework of the multiphase nature of expanded austenite, the decrease in the intensity of ferromagnetism can be also understood through the decrease in the $\mathrm{N}$ supersaturation which ultimately results in less $\mathrm{CrN}$ precipitate formation, ${ }^{14}$ effectively leaving less ferromagnetic $\mathrm{Fe}$ and Ni-enriched areas. $^{15,32}$ For areas with even lower $\mathrm{N}$ contents, this might not apply since the amount of $\mathrm{N}$ is well below the amount of $\mathrm{Cr}$ (around 18 at.\% in AISI 316L ASS) and the expanded austenite is then expected to behave as a solid solution. However, the decrease in the intensity of ferromagnetism in this region can be linked to a less pronounced change in the $\mathrm{Fe}-\mathrm{Cr}-\mathrm{Ni}$ atomic distances, which could also contribute to the ferromagnetic response. ${ }^{10}$ Even though the extent of the ferromagnetism seems to cover areas with rather low $\mathrm{N}$ content (see loops $\mathrm{J}$ and $\mathrm{K}$ in Fig. 3e), additional contributions from dispersed (i.e., inhomogeneous) ferromagnetic martensite traces $^{33}$ cannot be completely ruled out. At around $110 \mu \mathrm{m}$ away from the edge and further (region L), the ferromagnetic signal completely vanishes and the corresponding MOKE measurements 
resemble that of Fig. 3f, virtually exhibiting no hysteretic behaviour and, hence, no ferromagnetism.

Fig. 4a shows the evolution of the amplitude of the MOKE signal which can be taken approximately proportional to the magnetization (i.e., to the strength of the induced ferromagnetism). ${ }^{34}$ Interestingly, a prominent (half of the previous values) drop of the signal takes place when going from 15 to $20 \mu \mathrm{m}$ away from the edge, evidencing a pronounced decrease of the induced ferromagnetism. This coincides with the vanishing of the diverse magnetic contributions to the hysteresis loops (i.e., two-step loops) and might also be linked to the loss of the multiphase nature of expanded
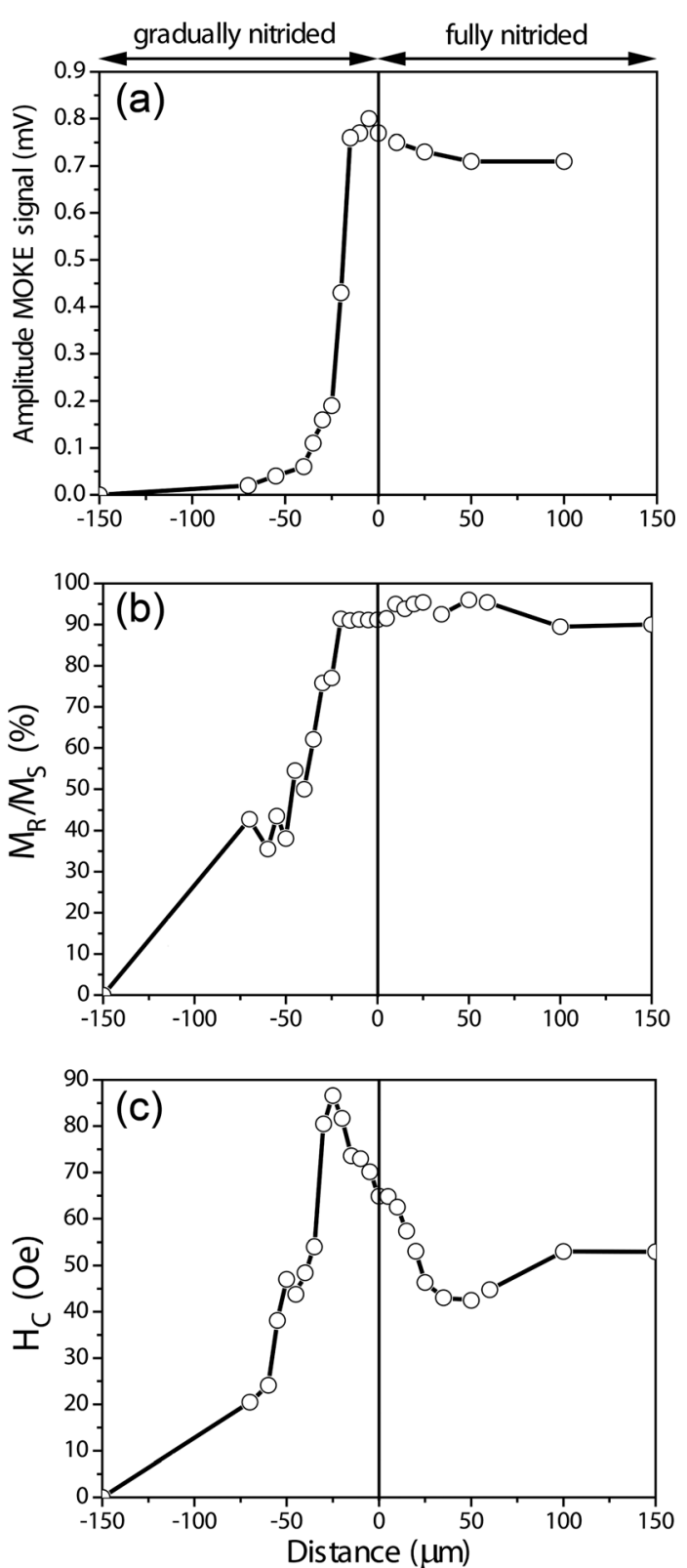

Fig. 4 Evolutions of (a) the amplitude of the MOKE signal, (b) the remanence-to-saturation magnetization ratio $\left(M_{R} / M_{S}\right)$ and (c) the coercivity $\left(H_{C}\right)$ along the gradually nitrided areas. The lines are connections between the data. austenite, which results in less ferromagnetic $\mathrm{Fe}$ and Ni-enriched areas. ${ }^{15,32}$ From distances at least $40 \mu \mathrm{m}$ away from the edge (below $\approx 14$ at.\% of $\mathrm{N}$ ), the MOKE signal is one order of magnitude lower than that of the fully nitrided areas, revealing rather mild nitriding conditions which most probably can be attributed to an incipient expanded austenite (i.e., a solid solution).

The remnant to saturation magnetization ratio, $M_{\mathrm{R}} / M_{\mathrm{S}}$, follows a trend similar to the $\mathrm{N}$ profile (Fig. 4b), while the coercivity, $H_{\mathrm{C}}$, exhibits a non-monotonic behaviour (Fig. 4c). The remanence remains large (above 90\%) in the fully nitrided area and up to $20 \mu \mathrm{m}$ away from the edge. This indicates that the material maintains a well defined out-of-plane easy axis up to around 25 at.\% of $\mathrm{N}$. This is ascribed to the large lattice expansion along the [100] direction. ${ }^{13}$ The reduction of $M_{\mathrm{R}} / M_{\mathrm{S}}$ as the $\mathrm{N}$ content becomes lower is ascribed to a weaker perpendicular anisotropy which results from a less pronounced out-of-plane lattice expansion, ${ }^{35}$ which is known to scale with the $\mathrm{N}$ content. ${ }^{19}$ The coercivity mainly depends on the ratio between magnetic anisotropy and saturation magnetization. ${ }^{36,37}$ The latter could be related to the intensity of induced ferromagnetism and the former could be assigned to the lattice expansion. Hence, the observed non-monotonic behaviour of the coercivity might be due to the dissimilar dependence of the induced perpendicular anisotropy and the strength of the induced ferromagnetism on the $\mathrm{N}$ content.

Although the correlation between coercivity and microstructure is still poorly understood, ${ }^{36}$ some studies have shown that the coercivity in magnetic materials depends on the occurrence of incoherent magnetization processes caused by the presence of defects. ${ }^{37}$ Thus, the CrN precipitates could act as pinning sites for domain wall movement, consequently affecting the coercivity, depending on their size and density. Interestingly, in the gradually nitrided areas close to the edge, the dispersion in the values of the mechanical parameters significantly broadens, the signal to noise ratio of the polar MOKE signal improves and the polar MOKE loops exhibit multiple magnetic contributions. This is consistent with the expected transition, from a nitrogen supersaturated solid solution to the multiphase structure of the expanded austenite as the $\mathrm{N}$ content increases, when plasma nitriding is performed at $400{ }^{\circ} \mathrm{C}$.

\section{Conclusions}

The influence of nitrogen content on the mechanical and magnetic properties of plasma-nitrided ASS has been studied using a combinatorial approach. Plasma nitriding with partial masking of a [100]-oriented 316L ASS single crystal has been demonstrated as a successful approach to obtain a varying $\mathrm{N}$ surface content on a single sample using a sole procedure. The obtained in-plane gradient of nitrogen concentration corresponds to a rather linear $\mathrm{N}$ profile that extends up to around $100 \mu \mathrm{m}$ into the masked area. The proposed methodology offers a fast and versatile route to obtain an in-plane gradient of interstitial species, leading to 
an in-plane functionally graded material. The hardness, reduced Young's modulus and $M_{\mathrm{R}} / M_{\mathrm{S}}$ lateral profiles qualitatively depict the lateral nitrogen profile, evidencing that nitrogen concentration is ultimately a central factor for the observed dependencies. A non-monotonic relationship between the coercivity $H_{\mathrm{C}}$ and the $\mathrm{N}$ concentration was observed. This can be linked to the complex evolution of the microstructure of the expanded austenite which mainly depends on the $\mathrm{N}$ content, nitriding time and temperature. Moreover, fingerprints of the expected transition from a nitrogen supersaturated solid solution to a multiphase nature of expanded austenite are elucidated along the gradually nitrided area.

We believe that the approach outlined in this study is of more general applicability to other material systems. This can be used not only for the basic studies of growth-structureproperty relationships but also to optimize plasma or other thermo-chemical treatments of functional materials; for example, the diffusional formation of ferrite from austenite in $\mathrm{Fe}-\mathrm{C}-\mathrm{X}$ systems $(\mathrm{X}=\mathrm{Mn}, \mathrm{Ni}, \mathrm{Cr}, \mathrm{Mo}, \mathrm{Si}, \ldots)^{7}$

\section{Acknowledgements}

This work was financed by the Research Foundation-Flanders (FWO), the KU Leuven Concerted Action (GOA/09/006 and GOA/14/007) programs, the 2009-SGR-1292 project of the Generalitat de Catalunya and the MAT2010-20616-C02 and MAT2011-27380-C02-01 projects of the Spanish Ministerio de Economía y Competitividad. E. M. thanks the FWO for financial support.

\section{Notes and references}

1 H. Koinuma and I. Takeuchi, Nat. Mater., 2004, 3, 429.

2 X.-D. Xiang, X. Sun, G. Briceño, Y. Lou, K.-A. Wang, H. Chang, W. G. Wallace-Freedman, S.-W. Chen and P. G. Schultz, Science, 1995, 268, 1738.

3 J. J. Hanak, J. Mater. Sci., 1970, 5, 964.

4 X. D. Xiang, Annu. Rev. Mater. Sci., 1999, 29, 149.

5 Y. Matsumoto, H. Koinuma, T. Hasegawa, I. Takeuchi, F. Tsui and Y. K. Yoo, MRS Bull., 2003, 28, 734.

6 I. Takeuchi, R. B. van Dover and H. Koinuma, MRS Bull., 2002, 27, 301.

7 C. R. Hutchinson, A. Fuchsmann, H. S. Zurob and Y. Brechet, Scr. Mater., 2004, 50, 285.

8 E. Richter, R. Günzel, S. Parascandola, T. Telbizova, O. Kruse and W. Möller, Surf. Coat. Technol., 2000, 128-129, 21.

9 T. Bell, Surf. Eng., 2002, 18, 415.

10 O. Öztürk and D. L. Williamson, J. Appl. Phys., 1995, 77, 3839.

11 E. Menéndez, A. Martinavicius, M. O. Liedke, G. Abrasonis, J. Fassbender, J. Sommerlatte, K. Nielsch, S. Suriñach, M. D. Baró, J. Nogués and J. Sort, Acta Mater., 2008, 56, 4570.

12 E. Menéndez, J. C. Stinville, C. Tromas, C. Templier, P. Villechaise, J. P. Rivière, M. Drouet, A. Martinavicius,
G. Abrasonis, J. Fassbender, M. D. Baró, J. Sort and J. Nogués, Appl. Phys. Lett., 2010, 96, 242509.

13 E. Menéndez, C. Templier, P. Garcia-Ramirez, J. Santiso, A. Vantomme, K. Temst and J. Nogués, ACS Appl. Mater. Interfaces, 2013, 5, 10118.

14 R. L. O. Basso, V. L. Pimentel, S. Weber, G. Marcos, T. Czerwiec, I. J. R. Baumvol and C. A. Figueroa, J. Appl. Phys., 2009, 105, 124914.

15 A. Martinavičius, G. Abrasonis, A. C. Scheinost, R. Danoix, F. Danoix, J. C. Stinville, G. Talut, C. Templier, O. Liedke, S. Gemming and W. Möller, Acta Mater., 2012, 60, 4065.

16 T. L. Christiansen and M. A. J. Somers, Scr. Mater., 2004, 50, 35.

17 M. P. Fewell and J. M. Priest, Surf. Coat. Technol., 2008, 202, 1802 .

18 T. L. Christiansen, T. S. Hummelshøj and M. A. J. Somers, Surf. Eng., 2010, 26, 242.

19 C. Templier, J. C. Stinville, P. Villechaise, P. O. Renault, G. Abrasonis, J. P. Rivière, A. Martinavicius and M. Drouet, Surf. Coat. Technol., 2010, 204, 2551.

20 J. C. Stinville, P. Villechaise, C. Templier, J. P. Rivière and M. Drouet, Acta Mater., 2010, 58, 2814.

21 S. Jegou, T. L. Christiansen, M. Klaus, C. Genzel and M. A. J. Somers, Thin Solid Films, 2013, 530, 71.

22 C. Tromas, J. C. Stinville, C. Templier and P. Villechaise, Acta Mater., 2012, 60, 1965.

23 A. Martinavičius, G. Abrasonis, W. Möller, C. Templier, J. P. Rivière, A. Declémy and Y. Chumlyakov, J. Appl. Phys., 2009, 105, 093502.

24 A. Martinavicius, G. Abrasonis and W. Moeller, J. Appl. Phys., 2011, 110, 074907.

25 G. Abrasonis, W. Möller and X. Ma, Phys. Rev. Lett., 2006, 96, 065901.

26 J. Perrière, J. Siejka, N. Rémili, A. Laurent, A. Straboni and B. Vuillermoz, J. Appl. Phys., 1986, 59, 2752.

27 G. Marcos, S. Guilet, F. Cleymand, T. Thiriet and T. Czerwiec, Surf. Coat. Technol., 2011, 205, S275.

28 P. J. Potts, in A Handbook of Silicate Rock Analysis, New York, Chapman and Hall, 1987, p. 336.

29 A. C. Fischer-Cripps, in Nanoindentation, New York, Springer, 2004, p. 85.

30 W. C. Oliver and G. M. Pharr, J. Mater. Res., 1992, 7, 1564.

31 J. C. Stinville, C. Templier, P. Villechaise and L. Pichon, J. Mater. Sci., 2011, 46, 5503.

32 M. Schröter, H. Ebert, H. Akai, P. Entel, E. Hoffmann and G. G. Reddy, Phys. Rev. B: Condens. Matter Mater. Phys, 1995, 52, 188.

33 J. Sort, A. Concustell, E. Menéndez, S. Suriñach, M. D. Baró, J. Farran and J. Nogués, Appl. Phys. Lett., 2006, 89, 032509.

34 Z. Q. Qiu and S. D. Bader, J. Magn. Magn. Mater., 1999, 200, 664 .

35 S. Grigull and S. Parascandola, J. Appl. Phys., 2000, 88, 6925.

36 D. Givord, M. F. Rossignol and D. W. Taylor, J. Phys. IV, 1992, 2, C3-95.

37 H. Kronmüller, K. D. Durst and M. Sagawa, J. Magn. Magn. Mater., 1988, 74, 291. 